\title{
Circulating carcinoembryonic antigen (CEA): Relationship to clinical status of patients with inflammatory bowel disease
}

\author{
A. H. RULE, C. GOLESKI-REILLY, D. B. SACHAR ${ }^{1}$, J. VANDEVOORDE, AND \\ H. D. JANOWITZ \\ From the Division of Gastroenterology, Department of Medicine, The Mount Sinai Hospital \\ and The Mount Sinai School of Medicine of the City University of New York, New York, USA
}

SUMMARY Plasma levels of circulating carcinoembryonic antigen (CEA) were measured by zirconyl phosphate gel radioimmunoassay in 112 patients with chronic inflammatory bowel disease. The levels were then related to category, extent, duration, and severity of disease, as well as to the ages and surgical status of the patients. The distribution of CEA levels and their mean values were significantly raised over the levels in 33 normal control subjects, and were similar among patients with ulcerative colitis compared with those with granulomatous bowel disease. Positive values were defined as those in excess of $2.5 \mathrm{ng} / \mathrm{ml}$. Positive assays occurred in $42 \%$ of ulcerative colitis patients, in $38 \%$ of Crohn's disease patients, and in $40 \%$ of the total group with inflammatory bowel disease. Among normal control subjects, only $3 \%$ were positive. Among inflammatory bowel disease patients, positive CEA assays occurred more frequently with more severe disease, more extensive anatomical involvement, younger ages, and shorter duration of disease. Those patients who had undergone total colectomy showed levels of circulating CEA and frequency of CEA positivity similar to those of an age-matched normal control group. Levels of CEA did not correspond with known cancer risk factors in patients with inflammatory bowel disease. Although rising or persisting plasma CEA values unrelated to severity and extent of disease may indicate an unfavourable prognosis in cancer, this study shows that a single CEA value in patients with chronic inflammatory bowel disease is not a reliable indicator of cancer risk.

Discovery of a tumour-specific antigen obtained from foetal gut and colon carcinoma in 1965 by Gold and Freedman subsequently was followed by reports of its isolation, characterization, and use in radioimmunoassay (Gold and Freedman, 1965a and b; Krupey, Gold, and Freedman, 1967 and 1968; Thompson, Krupey, Freedman, and Gold, 1969). It was termed the carcinoembryonic antigen (CEA) in accordance with the hypothesis that carcinogenic derepressive, dedifferentiating mechanisms had caused its expression. Recent studies have shown that small amounts of CEA are present in lung endothelium (LoGerfo and Herter, 1972), normal colonic mucosa (LoGerfo and Herter, 1972; Goleski, Janowitz, and Rule, 1972), and meconium (Goleski et al, 1972; Rule, 1973). Circulating CEA has been

${ }^{1}$ Please address requests for reprints to David B. Sachar, MD, Mount Sinai School of Medicine, 19 East 98th Street, New York, NY 10029.

Received for publication 14 August 1973. found in patients with cancer of the colon (Thompson et al, 1969; LoGerfo, Krupey, and Hansen, 1971) as well as with tumours of non-entodermal origin (LoGerfo et al, 1971; Moore, Kupchik, Marcon, and Zamcheck, 1971; Reynoso, Chu, Holyoke, Cohen, Nemoto, Wang, Chuang, Guinan, and Murphy, 1972). It has also been found in patients with chronic diseases such as alcoholic liver disease (Moore $e t$ al, 1971), Crohn's disease, and ulcerative colitis (LoGerfo et al, 1971; Moore et al, 1971; Rule, Straus, Vandevoorde, and Janowitz, 1972).

Isoelectric focusing of tissues from normal foetal, adult, or malignant sources in conjunction with the CEA radioimmunoassay has shown CEA-reacting fractions which can be classified as normal, tumourassociated, and tumour-specific CEA-reacting molecules (Goleski et al, 1972). While the specificity of the original CEA radioimmunoassay has been questioned, its use as a prognostic tool following 
surgery, chemotherapy, and/or radiotherapy in patients with cancer of the gut is widely accepted. Rising levels of circulating CEA are associated with primary or disseminating malignancy of poor prognosis (Reynoso et al, 1972; Zamcheck and Moore, 1972; Zamcheck, Moore, Dhar, and Kupchik, 1972; Moore, Kantrowitz, and Zamcheck, 1972; Dhar, Moore, Zamcheck, and Kupchik, 1972).

We therefore began a long-term study of patients with chronic inflammatory disease of the gastrointestinal tract at high risk for cancer of the colon (Fennessy, Sparberg, and Kirsner, 1968; Devroede, Taylor, Sauer, Jackman, and Stickler, 1971; Truelove, 1971). Plasma CEA levels in 112 patients with ulcerative or granulomatous disease were related to their age and surgical status as well as to the duration, severity, extent, and type of disease of the patients. The initial results are presented in this study.

\section{Materials and Methods}

Patients were referred from the Research Clinic for Ileitis and Colitis of the Mount Sinai Hospital or by research physicians associated with the National Foundation for Ileitis and Colitis, Inc. At the time of testing $20 \%$ of the patients were in remission, $35 \%$ had mild disease, $29 \%$ had moderate disease, and $16 \%$ had severe disease. Classic clinical, proctoscopic, radiological, surgical, and pathological criteria were used to establish the diagnoses, while the degree of severity was classified on the basis of simple clinical and laboratory criteria (acute abdominal, pain and tenderness, fever, active fistulous drainage, diarrhoea, rectal bleeding, and elevated white blood counts and sedimentation rates).

The patients had no renal or hepatic disease. Alcoholism or cancer was not present as ascertained by clinical methods. The randomly chosen ambulatory controls were free of all known diseases. None of the patients or normal controls smoked more than two packets of cigarettes per day.

Carcinoembryonic antigen radioimmunoassays were performed by the method of LoGerfo $e t$ al (1971). Duplicate samples were always assayed against known positive and negative controls. Standard CEA inhibition curves were also established. Serial bleedings on stable patients or normal controls over the period of one year established the standard error of the assay at $\pm 0.4 \mathrm{ng} / \mathrm{CEA} \mathrm{ml}$.

The anti-CEA used in the studies was absorbed with blood group substances and normal serum proteins before use. A band of identity was found with CEA and absorbed anti-CEA obtained from Dr Phil Gold with this antiserum. Plasmas containing more than $2.5 \mathrm{ng}$ of CEA per millilitre were considered positive.
Resuits

Table I shows the positive circulating CEA assays on sera obtained from patients with chronic inflammatory disease of the gastrointestinal tract. Patients with granulomatous disease showed $42 \%$ CEA positivity as opposed to $3 \%$ in the control group. The group with the most extensive disease, ileocolitis, showed the highest percentage of positive CEA assays $(55 \%)$. Of patients with ulcerative disease, $38 \%$ had significant levels of circulating carcinoembryonic antigen. Patients with the most limited form of inflammatory disease, ulcerative proctitis, had the lowest CEA positivity of all groups tested $(20 \%)$.

\begin{tabular}{lcl}
\hline Group Tested & $\begin{array}{l}\text { No. } \\
\text { Tested }\end{array}$ & $\begin{array}{l}\text { Percentage } \\
\text { Positive } \\
(C E A>2 \cdot 5 \mathrm{ng} / \mathrm{ml})\end{array}$ \\
\hline Granulomatous Disease & 64 & 42 \\
$\quad$ Regional ileitis & 35 & $36 \cdot 6$ \\
$\quad$ Ileocolitis & 20 & 55 \\
Colitis & 9 & 33 \\
Ulcerative Disease & 48 & 38 \\
$\quad$ Colitis & 43 & 40 \\
$\quad$ Proctitis & 5 & 20 \\
Total & 112 & 40 \\
Normal Controls & 30 & $3 \cdot 3$ \\
\hline
\end{tabular}

Table I Circulating CEA in patients with chronic disease of the gastrointestinal trace

The relationship of severity of disease to the presence of circulating CEA is shown in tables II and III. Patients who were in remission or had mild symptoms at the time of bleeding had similar CEA positivity in both disease categories. However, CEApositive patients with low disease activity who had ulcerative disease were only barely positive $(2.6$ $\mathrm{ng} / \mathrm{ml}$ ) whereas those with granulomatous disease sometimes showed high levels of CEA (up to $14.3 \mathrm{ng} / \mathrm{ml})$. Patients with moderate or severe inflammatory disease at the time of testing had

\begin{tabular}{lccll}
\hline Category & $\begin{array}{l}\text { Number } \\
\text { Tested }\end{array}$ & $\begin{array}{l}\bar{X} \text { CEA } \\
(\mathrm{ng} / \mathrm{ml})\end{array}$ & $\begin{array}{l}\text { CEA } \\
\text { Range } \\
(\mathrm{ng} / \mathrm{ml})\end{array}$ & $\begin{array}{l}\text { Percentage } \\
\text { Positive }\end{array}$ \\
\hline In remission & 6 & 1.5 & $0.4-2.6$ & 16.7 \\
Mild disease & 17 & $1 \cdot 3$ & $-0.7-2.6$ & 17.6 \\
Moderate disease & 11 & $5 \cdot 2$ & $-0.1-14.3$ & 63 \\
Severe disease & 7 & 9.6 & $0.3-19.585$ \\
\hline
\end{tabular}

Table II Carcinoembryonic antigen radioimmunoassays on plasma from patients with ulcerative disease related to clinical severity 


\begin{tabular}{lllll}
\hline Category & $\begin{array}{l}\text { Number } \\
\text { Tested }\end{array}$ & $\begin{array}{l}\bar{X} \text { CEA } \\
(n g / m l)\end{array}$ & $\begin{array}{l}\text { CEA } \\
\text { Range } \\
(n g / m l)\end{array}$ & $\begin{array}{l}\text { Percentage } \\
\text { Positive }\end{array}$ \\
\hline In remission & 11 & $2 \cdot 1$ & $0 \cdot 6-6 \cdot 7$ & 25 \\
Mild disease & 13 & $2 \cdot 8$ & $0 \cdot 1-14 \cdot 3$ & 31 \\
Moderate disease & 14 & $4 \cdot 6$ & $0 \cdot 3-23.9$ & 55 \\
Severe disease & 7 & $5 \cdot 2$ & $0 \cdot 7-12 \cdot 6$ & 86 \\
\hline
\end{tabular}

Table III Carcinoembryonic antigen radioimmunoassay on plasma from patients with granulomatous disease to clinical severity

substantially higher mean circulating levels of CEA as well as greater percentages of CEA positivity.

The relationship of CEA to duration of disease is shown in figure 1a. Carcinoembryonic antigen levels in patients with inflammatory bowel disease are distributed over a range nearly 10 times higher than that found in the normal control population. Highest levels of circulating CEA are found early in the disease. The relationship of CEA values to age of patients is shown in figure $1 \mathrm{~b}$. Elevated levels of circulating CEA ( $>2.5 \mathrm{ng} / \mathrm{ml}$ ) were generally found in patients under 35 years of age who had moderate or severe disease.

Surgical status of patients with inflammatory disease is shown in figure 2 and table IV. There is little difference in CEA levels between patients who had no surgery and those who had undergone subtotal resections of disease; but mean levels and range of CEA are much lower in the group with total colectomy and, in fact, fail completely within the

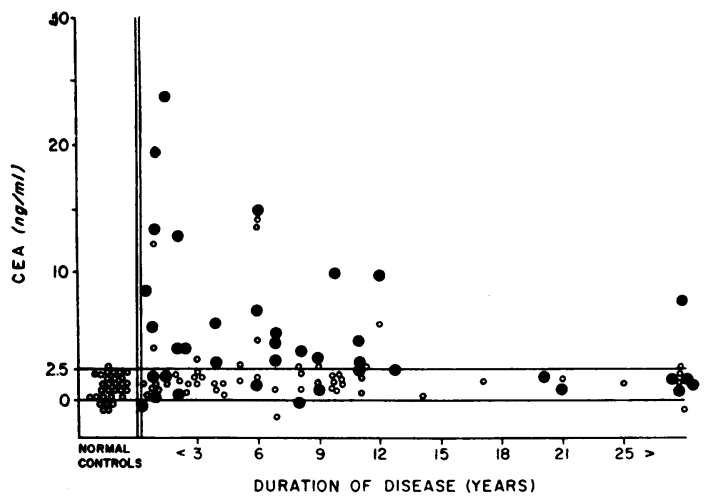

Fig 1a Relationship of circulating CEA to duration of inflammatory bowel disease.

Closed circles (O) indicate patients with moderate or severe disease; open circles $(O)$ represent patients in remission or with mild disease. Positive levels of CEA were those greater than $2.5 \mathrm{ng} / \mathrm{ml}$.

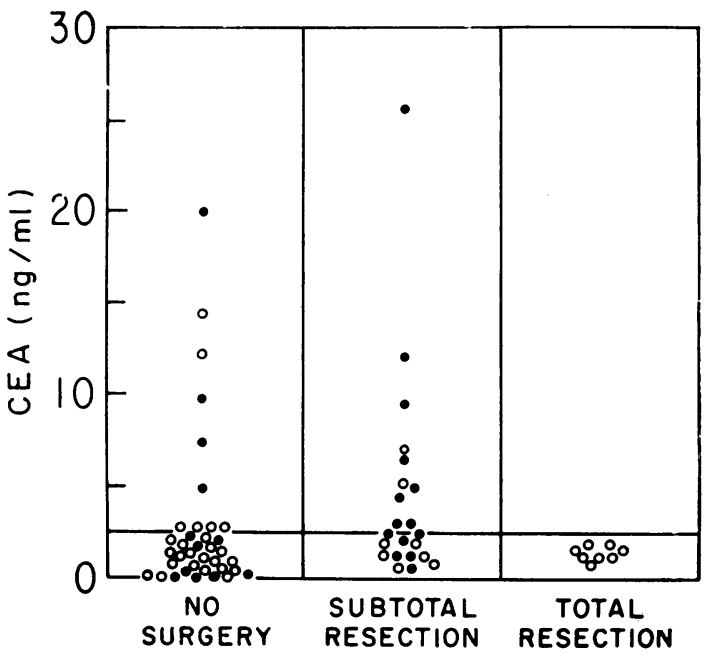

Fig 2 Relationship of surgical status of patients with inflammatory bowel disease to plasma CEA levels. Closed circles $(O)$ indicate patients with moderate or severe disease; open circles $(O)$ represent patients in remission or with mild disease. Positive levels of CEA were those greater than $2.5 \mathrm{ng} / \mathrm{ml}$.

normal range within six weeks after colectomy. Among patients with no surgery or subtotal colectomy, the results were the same with either ulcerative or granulomatous disease; the group undergoing total colectomy comprised only patients with ulcerative colitis.

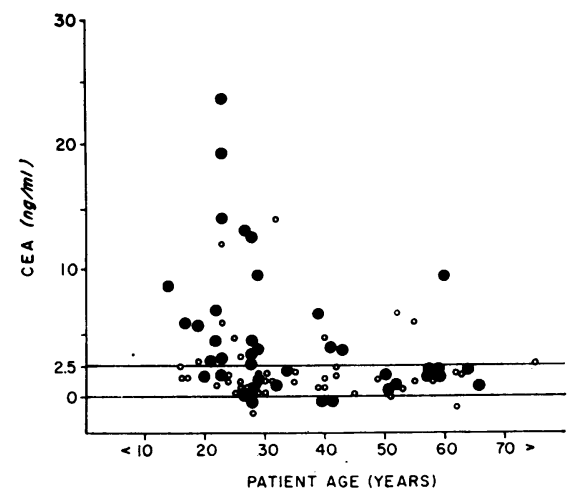

Fig 1b Relationship of age of patients to circulating levels of carcinoembryonic antigen. Closed circles (O) indicate patients with moderate or severe disease; open circles $(\bigcirc)$ represent patients in remission or with mild disease. Positive levels of CEA were those greater than $2.5 \mathrm{ng} / \mathrm{ml}$. 


\begin{tabular}{|c|c|c|}
\hline Category & $\begin{array}{l}\text { Percentage } \\
\text { Positive } \\
(>2.5 \mathrm{ng} / \mathrm{CEA} \mathrm{ml})\end{array}$ & $\begin{array}{l}\text { Range } \\
\text { (ng CEA/ml) }\end{array}$ \\
\hline \multirow{3}{*}{$\begin{array}{l}\text { No Surgery } \\
\text { In remission or with mild } \\
\text { disease } \\
\text { With moderate or severe } \\
\text { disease }\end{array}$} & $27 \cdot 8$ & $-0 \cdot 3-19 \cdot 3$ \\
\hline & $26 \cdot 1$ & $-0.3-13 \cdot 0$ \\
\hline & $30 \cdot 0$ & $-0 \cdot 1-19 \cdot 3$ \\
\hline \multirow{3}{*}{$\begin{array}{l}\text { Subtotal Resection } \\
\text { In remission or with mild } \\
\text { disease } \\
\text { With moderate or severe } \\
\text { disease }\end{array}$} & $50 \cdot 0$ & $0.2-23.0$ \\
\hline & $25 \cdot 0$ & $0.5-5.5$ \\
\hline & $64 \cdot 0$ & $0.1-23.0$ \\
\hline \multirow{3}{*}{$\begin{array}{l}\text { Total Resection } \\
\text { In remission or with mild } \\
\text { disease } \\
\text { With moderate or severe } \\
\text { disease }\end{array}$} & 0 & $0-0.3$ \\
\hline & 0 & $0-0.3$ \\
\hline & - & - \\
\hline Normal controls & $3 \cdot 3$ & $-0 \cdot 3-3 \cdot 0$ \\
\hline
\end{tabular}

Table IV Effect of surgery on CEA radioimmunoassays of sera from patients with chronic inflammatory disease of the gut

\section{Discussion}

We have found positive CEA levels in $40 \%$ of our series of 112 patients with inflammatory bowel disease. Substantial percentages of positive results have similarly been reported by other investigators; $30 \%$ by LoGerfo et al (1971), $12 \%$ by Moore et al (1972), and $35 \%$ by Snyder and Miller (1973).

Development of CEA radioimmunoassays had given rise to the hope for earlier detection of cancer for some patients at high risk for colonic cancer, namely those with inflammatory bowel disease (Thompson et al, 1969; LoGerfo et al, 1971). From our present studies, however, there is no evidence that the CEA level at one point in time correlates with any known risk factors for cancer of the gut. The present data confirm our earlier finding (Rule et al, 1972) that the incidence of CEA positivity was the same in both ulcerative and granulomatous bowel disease, even though ulcerative colitis is considered to carry the higher cancer risk (Fennessy et al, 1968; Devroede et al, 1971; Truelove, 1971). We have also found that CEA levels are higher earlier in the disease, whereas the cancer risk increases later. Moreover, CEA positivity in our present series was inversely related to age while the risk of cancer increases with advancing age.

Finally, circulating CEA levels greater than $5 \mathrm{ng} / \mathrm{ml}$ were found in approximately $15 \%$ of our population with chronic inflammatory bowel disease and at borderline CEA levels $(2 \cdot 5-4.9 \mathrm{ng} / \mathrm{ml})$ in $23 \%$ of these patients. None of these patients had any clinical indication of colon cancer. While patients with $2 \cdot 5-5 \mathrm{ng} / \mathrm{ml}$ are in a range similar to patients with primary adenocarcinomas of the colon, it is also the range for greatest variability in the interpretation of the significance of CEA radioimmunoassay (Rule et al, 1972; Zamcheck and Moore, 1972).

In support of recent findings of Moore et al (1972) those data suggest that a single measurement of CEA cannot be indicative of cancer prognosis in patients with inflammatory bowel disease. On the other hand, sequential CEA assays must be followed for increasing or persisting CEA levels to interpret any initial findings correctly, especially since Moore et al (1972) did not find any case of persisting antigenaemia in inflammatory bowel disease except in the presence of colonic adenocarcinoma. Increasing or persisting levels of CEA unrelated to increasing severity of disease in any given patient would therefore warrant a thorough clinical work up.

Total colectomy significantly reduced the occurrence of positive circulating levels of carcinoembryonic antigen. These data are in accord with the idea that CEA levels reflect the extent of bowel involvement and severity of disease. Such data also suggest that the CEA measured in the circulation of patients with inflammatory bowel disease was of colonic or ileal origin.

We initially proposed the idea that regeneration and/or degeneration of colonic mucosa in diseases involving the ileum or colon might simulate mucosal processes not unlike those found early in embryonic development or in carcinoma of the gut (Rule et al, 1972). The uncontrolled expression of many normal antigens has been found in other tumour systems. That certain glycoproteins may be produced which crossreact with CEA during periods of rapid mucosal turnover is not improbable. Certainly these glycoprotein antigens appear in measurable quantities in plasmas of patients with both ulcerative colitis and granulomatous disease.

In conclusion, our findings suggest that a single CEA radioimmunoassay by present methods cannot identify those patients with chronic inflammatory bowel disease who bear the highest risk for cancer. While current CEA radioimmunoassays may be of prognostic value in the postoperative evaluation of patients with cancer of the gut (Reynoso et al, 1972; Moore et al, 1972), our data suggest that more specific radioimmunoassays for antigens released by inflammatory processes might clarify the significance of the current broad-spectrum CEA radioimmunoassays. Long-term studies utilizing classic clinical criteria, current CEA radioimmunoassays, and more specific radioimmunoassays for CEA-reacting molecules released by regenerating and degenerating colonic mucosa may clarify the relationship of the various circulating forms of CEA-reacting molecules to inflammatory bowel disease and cancer. 
This work was supported in part by the National Foundation for Ileitis and Colitis, Inc, and the Research Division of Hoffmann-LaRoche, Nutley, NJ.

We are grateful for the samples of CEA and adsorbed anti-CEA supplied by Dr Phil Gold and his colleagues at Montreal General Hospital. The assistance of Miss Joan Bratton in keeping medical records and in preparing this manuscript is greatly appreciated.

\section{References}

Devroede, G. J., Taylor, W. F., Sauer, W. G., Jackman, R. J., and Stickler, G. B. (1971). Cancer risk and life expectancy of children with ulcerative colitis. New Engl. J. Med., 285, 17-21.

Dhar, P., Moore, T. L., Zamcheck, N., and Kupchik, H. Z. (1972). Carcinoembryonic antigen (CEA) in colonic cancer: use in preoperative and postoperative diagnosis and prognosis. $J$. Amer, med. Ass., 221, 31-35.

Fennessy, J. J., Sparberg, M. B., and Kirsner, J. B. (1968). Radiological findings in carcinoma of the colon complicating chronic ulcerative colitis. Gut, 9, 388-397.

Gold, P., and Freedman, S. O. (1965a). Demonstration of tumorspecific antigens in human colonic carcinomata by immunological tolerance and absorption techniques. J. exp. Med., 121, 439-462.

Gold, P., and Freedman, S. O. (1965b). Specific carcinoembryonic antigens of the human digestive system. J. exp. Med., 122, 467-481.

Goleski, C., Janowitz, H. D., and Rule, A. H. (1972). CEA-like antigens: Presence in tumor, normal colon and meconium extracts. Fed. Proc., 31, 639.

Krupey, J., Gold, P., and Freedman, S. O. (1967). Purification and characterization of carcinoembryonic antigens of the human digestive system. Nature (Lond.), 215, 67-68.
Krupey, J., Gold, P., and Freedman, S. O. (1968). Physicochemical studies of the carcinoembryonic antigens of the human digestive system. J. exp. Med., 128, 387-397.

LoGerfo, P., and Herter, F. P. (1972). Demonstration of tumor-associated antigen in normal colon and lung. J. surg. Oncol., 4, 1-7.

LoGerfo, P., Krupey, J., and Hansen, H. J. (1971). Demonstration of an antigen common to several varieties of neoplasia. Assay using zirconyl phosphate gel. New Engl. J. Med., 285, 138-141.

Moore, T. L., Kantrowitz, P. A., and Zamcheck, N. (1972). Carcinoembryonic antigen (CEA) in inflammatory bowel disease. J. Amer. med. A., 222, 944-947.

Moore, T. L., Kupchik, H. Z., Marcon, N., and Zamcheck, N. (1971). Carcinoembryonic antigen assay in cancer of the colon and pancreas and other digestive tract disorders. Amer. J. dig. Dis., 16, 1 -7.

Reynoso, G., Chu, T. M., Holyoke, D., Cohen, E., Nemoto, T. Wang, J. J., Chuang, J., Guinan, P., and Murphy, G. P. (1972). Carcinoembryonic antigen in patients with different cancers. J. Amer. med. Ass., 220, 361-365.

Rule, A. H. (1973). Carcinoembryonic antigen (CEA): activity of moconium and normal colon extracts. Immunol. Commun., 2, 15-24.

Rule, A. H., Straus, E., Vandevoorde, J., and Janowitz, H. D. (1972). Tumor-associated (CEA-reacting) antigen in patients with inflammatory bowel disease. New Engl. J. Med., 287, 24-26.

Snyder, J., and Miller, E. (1973). Collaborative CEA test results. In Proceedings of the Third Conference on Carcinoembryonic Antigen (CEA): Test Collaborative Study. Nutley, New Jersey.

Thompson, D. M. P., Krupey, J., Freedman, S. O., and Gold, P. (1969). The radioimmunoassay of circulating carcinoembryonic antigen of the human digestive system. Proc. nat. Acad. Sci. (Wush.), 64, 161-167.

Truelove, S. C. (1971). Ulcerative colitis beginning in childhood. New Engl. J. Med., 285, 50-52.

Zamcheck, N., and Moore, T. L. (1972). Ulcerative colitis/colon cancer: immunologically linked disorders? New Engl.J. Med., 287, 43.

Zamcheck, N., Moore, T. L., Dhar, P., and Kupchik, H. (1972). Immunologic diagnosis and prognosis of human digestive-tract cancer: carcinoembryonic antigens. New Engl. J. Med., 286, 83-86. 